\title{
DOCUMENTO Y REGISTRO GRÁFICO \\ EN EL ORIGEN ORIENTAL DE LOS SIGNOS \\ VISUALES PRECLÁSICOS Y LA PLENA VIGENCIA \\ EN ARCHIVOS CONTEMPORÁNEOS
}

\begin{abstract}
DOCUMENT AND GRAPHIC REGISTER ON THE ORIENTAL ORIGIN
OF PRECLASSIC VISUAL SIGNS AND THE FULL FORCE IN CONTEMPORARY FILES
\end{abstract}

\author{
Jaume ALAVEDRA i REGÀS \\ Universitat de Barcelona \\ hebed@yahoo.es
}

Resumen: Nuestro objetivo es el estudio gráfico de los documentos antiguos, en especial los jeroglíicos en sentido icónico. Una metodología amplia aplica la semiótica visual y cognitiva para grafismos. La aparición de sistemas escritos sigue la iconografía. Los documentos preclásicos se guardaban en archivos. La Biblioteca de Alejandría, que organizó Calímaco, representa la máxima institución cultural de la historia antigua.

Palabras clave: Documento. Semiótica visual. Preclasicismo. Iconos. Archivos.

Abstract: Our aim is the graphical study of ancient documents, namely the iconic sense on hieroglyphs. The methodology is close to visual and cognitive semiotics for graphs. The rise of writing systems is upon iconography. Preclassical documents were preserved into archives. The Library of Alexandria is the most important cultural institution of Ancient History, organized by Callimachus.

Key Words: Document. Visual semiotics. Preclassical. Icons. Archives and files. 
La historia no logra modificar radicalmente la estructura de un simbolismo arcaico. La historia añade continuamente significaciones nuevas, pero estas no destruyen la estructura del símbolo (Eliade, 1973: 119).

\section{HISTORIAYSIGNIFICACIÓNDELOSDOCUMENTOS ANTIGUOS}

Nuestro objetivo consiste en el estudio de los documentos antiguos y su carácter visual. En menor medida tratamos la interpretación contemporánea. El contexto histórico va añadiendo significaciones nuevas, que son estudiadas por la arqueología del lenguaje. En su dominio, esta trata la escritura conservada en documentos y textos, que guardan un simbolismo arcaico, tal como indica Eliade en la cita anterior. En esencia, la metodología es un sincretismo entre semiótica, historia y cultura con presencia hermenéutica, entendida entre el comprender y el explicar.

A lo largo de los siglos, la historia ha preservado la memoria del pasado en forma de documentos. Como registros gráficos asocian palabras, letras e imágenes en jeroglíicicos, inscripciones o emblemas. El universo de los signos presenta una cognición ligada a aspectos visuales. Los datos originan innumerables teorías científicas, centradas en aspectos cognitivos para el acto de escribir. El historiador comparte con la audiencia nociones generales sobre los datos para las formas visuales. La cultura participa del hecho de asignar sentido a los acontecimientos. En el relato acerca de cómo el conjunto de datos brutos y de nociones aplicadas alcanzan la consideración de expediente histórico emerge una de las cuestiones más complejas cuando se enfoca la realidad en la historia'.

En una secuencia de acontecimientos, las noticias sobre épica, poética, tragedia, comedia o sátira, en conjunto, connotan un momento, un autor y un pensamiento para un tiempo determinado. La información sobre los acontecimientos muestra cómo los datos se ajustan a lo real como icono de un proceso comprensible terminado, que viene a ser una estructura de la trama de su propio legado cultural (White, 2003: 117).

Los acontecimientos adquieren sentido por medio de diferentes narraciones de hechos acaecidos en el tiempo. Este constituye el vehículo expresivo sobre el que navega el documento. Con el paso del tiempo, el significado cristaliza en estratos temporales a los que acceder mediante la comprensión y la interpretación. En este sentido, la semiosis de

1 A través del tiempo, el grado de intervención escrita en la realidad supone una superficie gráfica. En ella se desarrolla un registro según contenidos y soportes. Los sentidos que se alcancen, sean rectos o figurados, envuelven procesos donde toman parte activa las metáforas, las metonimias o las sinécdoques. Para situar el concepto de semiótica, aplicado a los jeroglíicos, véase nuestro artículo del pasado congreso celebrado el año 2002 en Logroño (Alavedra, 2004). 
Peirce, como flujo constante e ininterrumpido de percepción y comprensión humanas, va añadiendo incesantemente significaciones nuevas. El mundo de la escritura es un producto de cultura de signos gráficos.

En este contexto, los documentos conservados emergen con una potente naturaleza visual. Son objeto de estudio por parte de la arqueología y la semiótica, que comparten intereses según las invenciones protohistóricas. En términos de cronología antigua, los signos aparecen varios milenios antes de nuestra era. Uno de los análisis del lenguaje, usado por Peirce, los sitúa y divide en tríadas, entre indicios, iconos y símbolos. Si se lleva a un tratamiento para aspectos gráficos hace unos seis mil años, a finales del período llamado Neolítico, predominan más los procesos icónicos que el resto. La idea determinante es que siempre permanecen vestigios de realidad en los iconos; mientras que los indicios, siendo el punto de arranque, autorizan la pesquisa pero sin demasiada interpretación, vienen a ser el primer contacto con el objeto, asociados al dato bruto. Con el símbolo cuya naturaleza es arbitraria, sucede algo parecido, exige una convención lejana e inapropiada para el contexto de creación y de sentido, que facilita más bien un análisis hermenéutico.

\subsection{SEMIÓTICA VISUAL Y COGNITIVA EN LOS GRAFISMOS}

Semiografía:

El grafismo, que apareció en la historia de la humanidad antes que el arte, la reconquista con un movimiento inverso. Los elementos semiográficos de la pintura universal son innumerables, multiformes: también en el gran arte figurativo, un gran número de trazados son, estatutariamente, grafismos por su origen manual, por su movimiento, por su Gestalt, su fuerza incisiva, su ritmo, su abstracción (Barthes, 1989: 71).

La escritura es un producto visual de la expresión humana en forma gráfica. Las relaciones entre verbalizad y no verbalidad de las figuras hacen que la significación dependa tanto del tiempo como del contexto. La comparación entre historia escrita, fijada accesible, y oralidad, inmediata perecedera, revela la estructura biológica de la mente y el cerebro. El grafismo aparece pronto como indica Barthes. En los trazos, la actividad cognitiva connota habilidad según la transmisión que hay entre pensamiento y expresión motriz. Los enfoques que propone el paradigma del cognitivismo disponen la invención en conjunción con la semejanza. En el ajuste de la perspectiva, remite al clasicismo de la similitudo y la comparatio (Klinkenberg, 2008: 54, n. 6). 
Cuando la escritura toma una apariencia visible se amolda a formas de masas de signos. En buena medida aparecen ilustraciones ya sean internas referenciales como los signos matemáticos, ya sean externas como los pictogramas o los logogramas. Ambos desembocan en la realidad, que da nombre a las palabras del léxico. La clasificación propuesta para estos signos en pictogramas, tipogramas e ideogramas hace visible los signos en la pintura. De otro modo cuando sigue aspectos lingüísticos origina vocabularios de naturaleza gramatical en la linearización o niveles de articulación (Cornu, 1983: 124-125).

\section{LA INVENCIÓN DE LA ESCRITURA EN EL ORIENTE ANTIGUO}

Recuérdese la historia que Sócrates narra en el Fedro, cómo Theut inventa la escritura y se la presenta al rey egipcio, alabándola como un invento de enorme valor para la humanidad, puesto que fortalecería infinitamente la memoria de los hombres. Pero el sabio rey de los egipcios le replicó: lo que tú has inventado no fortalecerá la memoria, sino que resultará en un debilitamiento de la memoria. Sócrates, pues, no veía en la escritura un progreso, y mucho menos pudo llegar a pensar que la palabra hablada pudiera ser rebasada (Gadamer, 1996: 187-188).

La invención de la escritura hace unos 6.000 años ocurre en dos contextos orientales simultáneamente: el de Mesopotamia y el de Egipto. En su origen constituye un invento útil para desarrollar un sistema gráfico. En la actualidad aparece como uno de los mayores logros de la civilización humana. Conduce a una mediación entre objetos, palabras de la lengua y comunicación entre los humanos. Muestra la coordinación entre invención de signos y su reproducción gráfica. Bastan algunos ejemplos para apreciar el valor cognitivo de la escritura. Por ejemplo tenemos el cuneiforme mesopotámico; los jeroglíficos egipcios, mayas o aztecas; los radicales chinos, japoneses o coreanos; o, los variados alfabetos derivados del fenicio, divulgados por el griego. En la historia de la humanidad, el número de escrituras inventadas ha alcanzado un número que dificulta una clasificación comprensible. En la tarea propuesta, el núcleo de la explicación histórica sigue la idea mesopotámica, egipcia, griega y hebraica del Antiguo Testamento. Como el domino es excesivamente vasto, requiere una acotación en la visión para el primer milenio antes de nuestra era, centrada en Egipto. El método usado es icónico, parte real aritmética; $y$ parte arbitraria, de sistemas sígnicos orientales. A este respecto, las primeras teorías sobre el origen de la escritura situaban la invención en los signos administrativos 
y fiscales. Hoy el vigor de esta teoría ha remitido y se añaden otros factores simbólicos relativos al poder, la cultura y la religión.

El marco cognitivo prehistórico imponía que los sistemas escritos no fueron concebidos para reproducir los lenguajes arcaicos. Tal como creía Sócrates, era difícil rebasar la palabra, según indica Gadamer. No obstante, las representaciones simbólicas de las palabras hicieron más realistas las técnicas de tratamiento de la información gráfica. Los períodos arcaicos, hace unos 6.000 años, conformaban una esencia pictórica. Dos mil años después abrían paso a la Edad del Bronce, adoptando formas en apariencia más abstractas que los modelos de objetos que referían. El proceso condujo a formar y estilizar un modelo, que disfrazó los trazos pictográficos de sus antecesores. Adoptada una visión conjunta entre semiótica y arqueología, observamos que signos y símbolos se iban conservando en estratos definidos de cultura material. La visibilidad dependía del tiempo y espacio. Por ejemplo, la colina de la Acrópolis de Atenas albergaba numerosos restos arqueológicos de primera magnitud, útiles para entender a los griegos y a la cultura occidental. Durante varios siglos fue el centro alrededor del cual gravitaba la vida política y cultural. Sin embargo, especialmente en el siglo $V$ antes de nuestra era, fue cuando resplandecieron la filosofía, la oratoria o el teatro.

Supone una ardua tarea excavar, organizar en archivos y catalogar los datos depositados a la manera como Penélope teje y desteje la urdimbre del tiempo mientras aguarda el regreso al hogar de su esposo Ulises. El invento de la democracia que protagonizaron fue un intento de guardarse en un sentido primigenio de la tiranía asiática. Los momentos controvertidos aparecieron en la derrota ateniense durante la Guerra del Peloponeso frente a Esparta. La unidades territoriales y administrativas, los Demos atenienses incidían sobre la política y movieron una ingente cantidad documental.

\subsection{LA ESCRITURA ANTIGUA COMO SISTEMA}

En su esencia, las escrituras constituyen sistemas mixtos, donde intervienen pictogramas, ideogramas, logogramas, silabarios, fonemas o determinativos. En su gramaticalización usan morfemas gráficos y semánticos, a la vez que fonogramas. El sistema de dibujos conlleva imágenes y sonidos de la lengua. La correspondencia semiótica entre objetos y unidades gramaticales ha facilitado el significado y el sentido en las cadenas habladas. La lengua y la gramática han promovido el desarrollo de los sistemas pictóricos desde la Prehistoria. En condiciones de intencionalidad y pertinencia lingüísticas, el mundo escrito ha hecho intervenir imágenes y palabras. La lengua desnuda es un mecanismo que no da el nombre a la cosa preexistente. El contexto y el significado van completando el proceso. Ahí intervienen sentidos y símbolos. En su evolución, la reproducción como vehículo mental articula la imagen en el mundo de 
la experiencia bajo el esquema y la corrección (cf. Marcenò, 2008: 39; también Escolar 2001; y Muñiz, 1997 y 1998). Su significado se revela mediante la definición canónica de la semiótica como representación de algo por alguien en algún sentido. Esta distingue visualmente las formas de expresión verbal y no verbal. De esta manera las palabras y los sonidos expresan tanto el pensamiento gráfico como el ágrafo. El grado de intervención en la realidad supone una superficie donde garabatear signos en correlación con los sonidos. La idea viene a desarrollar un registro acorde a los contenidos y los soportes, cuyos sentidos, sean rectos o figurados, envuelven procesos metafóricos, metonímicos o sinecdóticos.

\subsection{DESCIFRAMIENTOS DE LENGUAS ANTIGUAS EN LA TEORÍA COGNITIVA}

La escuela del cognitivismo ha desarrollado un conjunto de elaboradas estrategias acerca de la percepción. En relación a la paleoescritura, los primeros postulados parecían recaer en los silabarios. Tales conclusiones intentaban arrojar luz sobre la imposibilidad de pronunciar por sí mismos los valores consonánticos. En la segunda década del siglo XIX, el descifrador de los jeroglíficos egipcios, Jean-François Champollion, lo realizó gracias al conocimiento inaudito de la lengua copta. Propuso una tipología jerárquica elemental de signos escritos que sigue vigente actualmente. En breve, distinguía, para el habla, los signos que representan la condición de real y los que lo hacen gráficamente con transmutaciones gramaticales. De este modo Champollion hacía recaer en la fonología una parte sustancial no solo de su teoría del desciframiento sino de la estructura de las lenguas antiguas. Varias décadas posteriores, el desciframiento del cuneiforme por Rawlinson ayudó a considerar los silabarios.

Estos descriframientos ocurrieron a mediados del siglo XIX, cuando el conocimiento del cuneiforme comenzó a revelarse por una variante tardía: el persa aqueménide, con una cronología situada entre los siglos VI y IV antes de nuestra era. El danés Carsten Niebuhr copió un repertorio en Persépolis en el siglo XVIII. Las inscripciones eran trilingües: una lengua era de gran simplicidad con unos 40 signos, casi en el límite de la naturaleza alfabética; y dos lenguas eran silabarios o ideografías. Cada uno de los tres registros presentaba gran coherencia. Llevó a decirse que era una única lengua: el persa antiguo, cuyo origen cabía situarlo en la genealogía del indoiranio similar al sánscrito. Grotefend (1802) mostró que las palabras iniciales asignaban nombre, títulos y genealogía a un personaje como el rey, acorde con las ideas preconcebidas para el arameo, ya conocido entonces.

La tercera lengua de este recorrido por lenguas semíticas, el acadio se descifró a partir de antropónimos. Apareció en forma de variedades y diferencias locales o cronológicas, 
de manera que inició la idea de un laberinto de lenguas sinónimas regionales. El primer paso fue considerarlas semitas, hipótesis, que con matices, ha resultado correcta. Entonces la Asiriología avanzó con rapidez con los trabajos de Friedrich Delitzsch, Benno Landsberger y Wolfram von Soden. Tras el acadio, llegó el turno al sumerio en el siglo $X X$, sin parentesco establecido. Como lengua hablada murió a mitad del II milenio, pero continuó en la liturgia de Babilonia, cuyo clero la conservó y guardó en forma de textos para recitar. Estudiosos del sumerio fueron Thureau-Dangin o Poebel, más recientemente Civil.

En fin y como resumen del apartado anterior y antes de pasar a la teoría sobre iconos y símbolos, la disciplina semiótica constituye la forma más directa de analizar el carácter visual de las culturas antiguas. Dado que los documentos preservados son escasos y en condiciones de frágil conservación, la arqueología ha desarrollado técnicas de interpretación basadas en los estratos superpuestos. Como ciencia ha proporcionado una clara comprensión de los restos significantes. El concepto de semiosis de Peirce, como flujo de consciencia conlleva una teoría del conocimiento, una epistemología y una ontología ininterrumpidas desde la antigüedad. La fuente de la semiosis reside en los vestigios culturales. En especial para la escritura, los documentos conservados en forma gráfica son el resultado de la técnica que los originó. Benjamin indica que: “Con la palabra técnica, introduzco el concepto que permite someter los productos literarios a un análisis social directo" (2015: 11), con lo que expresa el acceso repetido a grapheion, los archivos. Este modo de encontrar el límite del hipergrafismo escrito o animado, permite múltiples lecturas semióticas.

El concepto de papiro es, por ejemplo, sintomático. La idea que hay detrás de este vocablo ha servido para dar nombre a la planta; a su vez es la médula que provee las tiras para la confección del material de elaboración; y también, para indicar el documento obtenido. Esta polisemia cognitiva es común para muchos conceptos de orden paleográfico, por ejemplo, las nociones de documento, texto, arte rupestre, archivo o biblioteca. Ahora bien, sucede lo mismo con otros conceptos más abstractos tales como los de faraón, monarquía, estatua, templo, palacio, tumba, maravilla de la antigüedad o, entre otros, por citar un solo ejemplo más, imperio.

\subsection{ANTIGUOS ICONOS Y SÍMBOLOS}

En la tarea conceptual propuesta en la teoría sobre iconos y símbolos, aquellos resultan fundamentales; no tanto, estos. El núcleo de la explicación histórica está basado en el pensamiento mesopotámico, el egipcio, el griego y el hebraico del Antiguo Testamento. Como el domino es excesivamente vasto, acotamos la visión para el primer milenio antes de nuestra era y nos centramos en el Egipto faraónico. El método usado se ciñe al 
concepto de icono, con una parte real acorde con la historia del origen oriental para los sistemas visuales de numeración y cómputo. A este respecto, las primeras teorías sobre el origen de la escritura sitúan la invención para usos administrativos y fiscales, teoría que ha remitido, aceptando otras nociones simbólicas de naturaleza cultura y social más productivas. Si adoptamos una visión conjunta, es decir, interrelacionada entre semiótica y ciencia arqueológica, los antiguos signos y símbolos se conservan a disposición de los usuarios en estratos bien definidos de cultura material. Van asociados a la visibilidad según dimensiones espaciales y temporales arcaicas. Permanecen acumulados en forma de archivos o piezas sueltas descontextualizadas.

\section{LA BIBLIOTECA COMO ARCHIVO DE SIGNOS: PROTAGONISTAS Y TÉCNICAS}

La primera visión innovadora que persigue la eterna utopía del acceso universal al conocimiento humano es la de la biblioteca. El deseo de tener todas las bibliotecas disponibles en el propio ordenador como elemento más difundido en nuestra sociedad es un deseo que retoma los antiguos mitos de la humanidad. En un lugar preferente, la excelencia de la Biblioteca de Alejandría destaca como la primera gran idea de Enciclopedia Universal. Ahí se barajan, entre otros, un sinfín de conceptos: Epigrafía, paleografía, papirología.

Documentos históricos, archivos, bibliotecas, hemerotecas, discotecas, compacotecas; papiros, pergaminos, vitelas, escritos a mano, escritura, jeroglíficos, alfabetos, documentos, textos (anapistógrafos — una sola cara-, opistógrafos — dos caras-, palimpsestos - reusados-) manuscritos, cuadernillos, copias, encuadernaciones, hojas plegadas, impresos, formatos de libro, cuadernos plegados, cuadernos cosidos, hojas, páginas, códigos, tablillas (barro, cera — polípticos—, madera), papel de ciervo, papel de agave, papel amato (plegados en forma de acordeón como pendones de Castilla), rollos, códices, codicilos, compilaciones, declaraciones, decretos, edictos, proclamaciones, bulas, breviarios, recopilaciones de fórmulas farmacéuticas o incrustaciones.

En la tarea propuesta, el núcleo de la explicación histórica sigue las ideas de los mesopotámicos, egipcios — con mayor presencia-, griegos y hebreos del Antiguo Testamento. Como el domino es excesivamente vasto, requiere una acotación en la visión para el primer milenio antes de nuestra era. El método usado es icónico, parte real de cómputo aritmético; y parte arbitraria, de sistemas sígnicos orientales. A este respecto, las primeras teorías sobre el origen de la escritura situaban la invención en los signos administrativos y fiscales. Los protagonistas de este mundo son los escribas. Los copistas y amanuenses en Egipto y Mesopotamia formaban escuelas que inventaban y reinventaban textos sin descanso. El trazado era a mano y con soltura caligráfica. Los 
documentos aparecían en paneles monumentales o cursivos. El resultado dio lugar a diversos sistemas: a los jeroglíficos sumerios y egipcios; al cuneiforme acadio e hitita; al cursivo demótico; y a los alfabetos fenicio, griego, latino o copto. Las superficies donde exponían los trazos eran muy variables y dependían de los materiales que tenían a mano. Para el sumerio y el acadio, las tabillas de barro eran el medio más económico por lógica en un ambiente donde abundaba el barro pero escaseaba la piedra. La plasticidad de la arcilla ayudaba a moldear a voluntad tanto la superficie como el tamaño. No exigía la talla o el picar la piedra. El sumerio era una lengua aislada, sin estar relacionada con ninguna otra, aglutinante que formaba cadenas de palabras con adición de múltiples morfemas a la raíz. Hay cierto paralelismo lingüístico con el etrusco y, en la actualidad, con el vasco. En la tipología de las lenguas, sus raíces son desconocidas.

En la evolución de los sistemas escritos, la lingüística ha tenido que considerar la linealidad como sarta de signos en cadena para una concatenación infrecuente en las aglutinantes. Ahora bien, algunas de estas consideraciones son distintas en los principios para los jeroglíficos egipcios. Esta lengua afroasiática seguía parentescos semíticos. De entrada y para los materiales, disponían de abundante piedra y plantas de papiro. La disponibilidad de materiales motivó, por una parte, un uso estático sobre los muros de las construcciones o, uno móvil y exento en objetos votivos como los ushebtis o en los cascotes llamados ostraca. Además llevó el uso de los papiros a un extremo inaudito, de manera que el Nilo ha sido identificado con el uso de esta planta. Por tanto la mayor parte de códigos conservados provienen de papiros convencionales, donde las imágenes e ideas se entendían según su propia cultura (Frandsen, 1997: 93).

En el antiguo Egipto existieron dos tipos contrapuestos de las llamadas Casas: las de la Vida en los templos, cubriendo funciones caligráficas litúrgicas de culto diario; y las de la Muerte, con servicios de momificación. Las casas de la Vida representaban los centros de aprendizaje escolar para los escribas que seguían la carrera burocrática en la corte real.

En la antigua Grecia, si no consideramos los libros, permanece una ingente cantidad de documentos de tipo político, administrativo, jurídico y forense. Los primeros rudimentos de bibliotecas aparecieron institucionalmente en época clásica a mediados del primer milenio. La adopción a una escala inaudita por primera vez en la historia del alfabeto griego impulsó el conocimiento hacia unos límites insospechados. Atenas asumió el liderazgo occidental del conocimiento, facultado por la Academia, el Liceo y las escuelas de epicúreos, estoicos o cínicos. La indisoluble asociación entre inscripción y sociedad que la produce queda reflejada en los ostraca griegos del siglo V. En las deliberaciones políticas, la Asamblea popular era la encargada de decidir las cuestiones que atañían a la ciudad. El uso como arma política de deliberación se llevaba a cabo, incluso hasta para las proscripciones. El presidente en el ejercicio del cargo de las pritanías sometía a la 
congregación los temas imperiosos. El sufragio, en el recuento epigráfico, era registrado en ostraca.

En estas formas mínimas, la producción de sentidos permitía separar un significante de otro en los engarces de la cadena de signos pronunciados. Ya lexicalizados, los vocablos se enlazaban por medio de ligaduras, como en los sistemas cursivos del hierático. Es común suponer que los signos de puntuación eran inexistentes. Simplemente no eran explícitos. El trazado del signo, el ductus, era individual y característico del escriba. En su oficio llegaba a hacer patente y ostentar en alto grado un dominio caligráfico entre los hebreos. Este hecho resaltaba al autor. Uno de los ejemplos paradigmáticos de la dimensión tardía de cambios ortográficos ha recaído en los caracteres arábigos de las antiguas comunidades preislámicas. En ellas se mantenía inalterable el sistema de consonantes aisladas para el llamado cúfico, hasta que aparecieron las vocales por razones de desambiguar, entrada la Edad Media, que junto a signos diacríticos aplicaron soluciones a las polisemias y homonimias.

El simple trazado de un grafema permitía una identificación directa con la referencia. Por ejemplo, una cabeza desnuda de perfil denotaba una cabeza y poseía un sonido: sag en sumerio; tep, en egipcio. Esta asignación planteaba el inconveniente irresoluble para los conceptos abstractos sin referente inmediato. No obstante, la misma cabeza en concreto podía representar uno de los géneros humanos, el masculino, cuando el femenino lo hacía por medio de la sinécdoque del triángulo púbico. En este sentido, los antiguos escribas introducían el uso de sistemas figurados como la metonimia en velas hinchadas por el barco; como la metáfora, en la mano para dar; y como la sinécdoque, en la copa medio llena para la cerveza. Mediante este sencillo proceso deslizaban con facilidad el significado entre referente y referido. El resultado concordaba con analogías lógicas creadas para usos concretos como era usar tres trazos paralelos para indicar el plural de los sustantivos. Otro ejemplo, el cetro hega, intacto de marfil depositado al lado del difunto, constituía la evidencia metonímica de símbolo de poder para el personaje aristocrático y permitía apreciar la posición jerárquica (Vernus, 2011: 30). En Sumer, por ejemplo, la asociación de un signo de pájaro más un huevo, significaba el verbo "engendrar"; el de la montaña más mujer, indicaba sirviente o esclava femenina. El proceso contenía una lógica interna definida, donde cada grafema específico asociaba grafema e idea significante. Sin embargo no resolvía ni polifonías ni polisemias. Los signos de clasificación recaían en los determinativos. A tal respecto el signo sumerio $K A$ designaba a la vez la boca, los dientes, la nariz, la palabra o el verbo hablar; hecho muy parecido al signo egipcio re para la boca. El funcionamiento oral nos es totalmente desconocido.

En términos de escritura, las culturas antiguas adoptaban un modo de razonamiento propio, donde los registros ajustaban lengua a tecnología escrita. Los elementos 
gráficos ocupaban superficies planas discontinuas con elementos gramaticales sin interrupción. En la evolución temporal, los pictogramas habían sido los primeros en aparecer e impulsaron lo rupestre a lo gramatical. De carácter icónico en la globalidad, identificaban directamente la noción a expresar, dominando la parataxia, que añadió enlaces asindéticos para provocar la hipotaxia, análogamente al latín.

\subsection{TEORÍA SÍGNICA DE LOS DOCUMENTOS ANTIGUOS}

En las escrituras antiguas, los iconos asociaban objeto a signo; mientras que el índice era natural, sin intervención humana, apenas aparecía en la escritura. El icono presentaba una mayor predisposición al uso por su participación de lo real. Ahora bien quedaba el símbolo, que vivía alejado de la realidad y devenía puramente convencional. Este se usaba en campos como la religión: el pez o la cruz para el cristiano. En cuanto a a la gramática, la equivalencia entre objeto y grafema devenía nula en indicios; parcialmente motivada en iconos y arbitraria en símbolos. Desde las pinturas rupestres paleolíticas, el pictograma cobró fuerza como reflejo propiciatorio. Luego apareció la complejidad en las estructuras que impuso los ideogramas. Más tarde, el grado de evolución idiomática hizo emerger fonogramas, logogramas y determinativos. El camino estaba despejado hacia los alfabetos.

La aparición de los ideogramas ocurrió en las fases más tempranas. La economía de los signos funcionaba a cualquier nivel y en la formalización de ideas tendió a estilizar las palabras más frecuentes. Simplemente trasladaban el objeto estilizado al signo. Los ideogramas representaban el sentido de la palabra adjunta y concordaban con el concepto. El uso decantó la balanza a favor de las facilidades de expresión icónicas. El resto tomó el sonido del grafema en valores fonéticos o silábicos para construir un significado compuesto.

En las sílabas la secuencia de los sonidos se representaba mediante un grafema. En caso de varios sonidos, estas formaban fragmentos con igual pronunciación. El proceso siguió formando nuevos vocablos. La silabización y adaptación al cuneiforme originó variantes como Ebla, Alalakh o Ugarit. Estas adaptaron sus listas léxicas que incluían palabras sumerias con traducciones al semítico occidental. Son importantes porque representaban un uso correlativo de signo logográfico a signo silábico tanto en el sumerio como en el semítico (Civil, 1982, 22). Así el cuneiforme al evolucionar conformó los sistemas babilonios, asirios o ugaríticos; e intervino sobre luvitas o hurritas. El neo-asirio fijó cada signo cuneiforme con su valor específico, que había sido variable en tiempos del sumerio, en la nueva forma significante (Civil, 1992). Alcanzaron tal esfuerzo de creación sígnica y ortográfica, que ha sido llamado la reforma de los escribas cancilleres en tiempos del Código de Hammurabi. La conclusión es que, para el primer 
milenio, los escribas potenciaron sistemas mixtos logo-silábicos donde los logrogramas se enroscaban entre comentarios exegéticos.

En cuanto a los archivos, en un principio acumularon un ingente material documental. Al crecer estos demandó una solución como germen de la formación de bibliotecas. En las ciudades mesopotámicas del segundo milenio, ya hay prototipos rudimentarios. La idea de crear bibliotecas emergió para conservar las tablillas y el registro de actividades económicas, administrativas, ligadas al culto diario. Sin el control de la historia en lugar especializado para almacenar documentos, no conservaban la memoria. Este espacio estaba regido por una casta sacerdotal residente especializada. Los documentos se escribían, por una parte, en cuneiforme y más tarde en acadio para el Creciente Fértil; y, por otra, en jeroglíficos o cursivo hierático en ambientes nilóticos. Las bibliotecas en función de archivo más conocidas fueron la de Asurbanipal en Nínive, Ebla, Lagash o Mari; para los egipcios, El Amarna u Oxirrinco. La colección documental constituía, en un caso, tablillas modeladas a mano con arcilla; o, en el otro, papiros pegados en hojas y estas, en volúmenes. En la colección más completa de Nínive, los documentos llegaron a miles de ejemplares; y esa suma es cercana en Oxirrinco. Contenían compendios gramaticales; listas en diccionarios o listas oficiales de ciudades; papiros administrativos o ejemplares relativos a la correspondencia internacional en varias lenguas, las ciencias, el arte o a la religión.

\section{ALEJANDRÍA, CUNA HISTÓRICA DEL HELENISMO}

Consecuencia del legado de los generales de Alejandro Magno, aparecieron a continuación las primeras instituciones de carácter enciclopédico: el Faro, el Museo y la Biblioteca de Alejandría. La leyenda no ha dejado de crecer desde entonces y connota una de las mayores utopías, no tanto ucronías, de la historia del conocimiento humano. La organización bibliotecaria más importante de la oicumené, la tierra habitada, recae en el traslado de Demetrio de Falerón a la ciudad en las últimas décadas del siglo III. EI encargo oficial de catalogación de papiros lo recibieron Zenódoto de Éfeso y el poeta Calímaco de Cirene. Este fue el máximo exponente de la cultura de realidades poéticas (Selden, 1988:301). Su obra Pinakes es el primer catálogo temático de la historia en forma de índice. El título es elocuente: "Tablas de personas eminentes en cada una de las ramas del aprendizaje, junto con una lista de sus escritos". Su extensión alcanzaba un centenar de libros y, con ello, venía a superar las obras del arcaico Homero. El índice poseía amplios conocimientos de retórica, leyes, épica, teatro, poesía, historia, medicina, matemáticas, ciencias naturales y misceláneas. Cada entrada remitía a autores en orden alfabético, de manera que adjuntaba una noticia biográfica. Por eso, añadía un conjunto de datos significantes, que connotaban una breve ontología para cada autor. También 
recurría al origen y presencia de clasificaciones bibliográficas. Provocó tal impacto en la opinión que preparó el árbol de Porfirio. En su evolución condujo a la arabización medieval, enlazado con la tradición de Alcuino de York, Ockham o, en el barroco tardío, de Leibniz. En resumidas cuentas, la clasificación como herramienta de organización para el bibliotecario había nacido en Calímaco. La traducción de taxonomías como normas originó sistemas de clasificación, cuya representación documental denotaba en su ordenación del sujeto el empleo de símbolos. En estas condiciones el taxón promovió un orden, que es central para la hermenéutica del sentido. La interpretación conllevaba la idea de comprender los documentos y dotarlos de significado. Así consolidó la diversidad documental y encadenó referencias a contenidos ${ }^{2}$.

En su tiempo, Calímaco representó el mayor ingenio poético y teórico de las letras. Escribió sobre epigramas e himnos, según modelos arcaicos. Aún hoy son fundamentales para entender los géneros literarios. Si se aprecia una referencia programática, es obligado su conocimiento bibliotecario. Entre sus discípulos, Apolonio de Rodas ha contribuido a su difusión. La obra del cirenaico influyó en Horacio o en Virgilio. Solo cabe añadir un dato más, Propercio es conocido como el "Calímaco romano".

\subsection{LA BIBLIOTECA DE ALEJANDRÍA}

En el tercer siglo emerge la Biblioteca de Alejandría como una institución de las más singulares. El catálogo que poseía era un conjunto de índices nunca vistos. No ha sobrevivido. Sólo es conocida por citas clásicas que mencionan la organización del conjunto documental, básicamente formado por papiros. En las fuentes clásicas del cambio de era, el geógrafo romano, Estrabón relata que se encontraba en la zona portuaria y en estrecha vecindad al Museo. Nada casual resulta el hecho y es significativa la concentración del conocimiento en instituciones complementarias. Los alrededores albergaban una serie de jardines, zoológicos, salas de disección, laboratorios, estancias dormitorios y de reuniones ${ }^{3}$. A excepción de alguna referencia histórica muy posterior, el contenido de los volúmenes o de los rollos de papiro, el trabajo diario de los sabios y sus condiciones de vida, o las herramientas de trabajo y de clasificación, son totalmente desconocidos. El hito más importante quizás entre los documentos antiguos es que fue la más grande y prestigiosa del mundo antiguo, obra del primer Diadoco de Alejandro Magno, el general Ptolomeo Sóter. Llegó a alcanzar el millón de documentos manuscritos

2 Mientras que la poesía de Calímaco presenta rasgos de alienación, el proyecto bibliotecario resulta ser un esquema histórico de gran ingenio, afectado por el pathos griego (Selden, 1998: 408). La idea de una institución de este tipo partió del primer rey Tolomeo, Sóter, y se consolidó con su hijo, Filadelfo, entrado el siglo III antes de nuestra era.

3 El conjunto componía un complejo muy parecido al que hoy existe en los alrededores de la ciudad francesa de Niza. Los organizadores han tomado el modelo de esta utopía alejandrina. 
con profusión gráfica de signos y esquemas científicos. Era la promesa de una cultura científica brillante, de primer orden. La actividad entre sus paredes llegó a ser frenética. La destrucción de la Biblioteca de Alejandría aun hoy constituye uno de los mayores enigmas de la civilización occidental.

El proyecto de la construcción de una institución que albergara y acumulara el conocimiento cambió el signo de la Historia Antigua. Realizado bajo el patrocinio de los macedonios, esta institución trataba de parecerse al ateniense Liceo aristotélico pero con la innovación de la conservación de papiros. Ciencias y artes conjuntaron el anejo Museion para dar alojamiento a sabios, poniendo a su suposición la más extensa colección bibliográfica de rollos de papiro. Los estudios sobre el Museo y la Biblioteca de Alejandría han servido para determinar su función y otros aspectos técnicos sobre los índices y los catálogos. Los ensayos sobre la enseñanza y la gramática helenista han facilitado el conocimiento de la conservación y docencia en esbozos de papiros. Sin embargo, la consulta de biografías de personas que la conocieron de primera mano al trabajar en sus estancias ha sido, sin duda, una aportación imprescindible. La consulta de las biografías de los matemáticos y astrónomos Teón y su hija Hipatia nos ofrecen un conocimiento fundamental para la historia de las matemáticas o la astronomía.

El Museo de Alejandría poseía una segunda biblioteca donde depositaba los fondos sobrantes de la biblioteca principal, el Serapeum. Estaba ubicado varios centenares de kilómetros Nilo abajo en el antiguo centro administrativo de Saqqara. Su situación era en el templo de Serapis. Fue fundado por Ptolomeo III. Sirvió de puente entre la cultura egipcia y la cultura griega, y se convirtió en centro de investigaciones científicas tras la destrucción del Museo. Fue clausurado y destruido tras los edictos del 391 de nuestra era por el emperador Teodosio I contra la cultura pagana.

\subsection{PÉRGAMO, EL MODELO RIVAL}

El otro gran centro cultural de la antigüedad fue la ciudad de Pérgamo. Situada en Misia, en la Asia Menor, cercana a Troya, alcanzó una fama que la hizo rivalizar con Alejandría. Si bien la actividad cultural de la ciudad asiática no duró tantos siglos ni dejó una impronta tan marcada, su prestigio fue incuestionable. Los reyes Atálidas crearon un centro de primer orden en el conocimiento como empresa de mecenazgo. Varios aspectos remarcables destacaron a Pérgamo sobre el resto de ciudades orientales a excepción de Alejandría: la invención del equivalente del papiro, el pergamino como piel ovina repulida; y la colección, colocada en una galería, de bustos de autores famosos.

En las primeras generaciones de los textos ptolemaicos el uso del papiro para documentos administrativos alcanzó una extensión predominante. Se usó de manera tan corriente que a nuestro juicio, representa la asunción egipcia de la cultura a gran 
escala de la recién llegada de los macedonios. No solo el hecho de adoptar el protocolo faraónico les hizo más nilóticos sino que fueron estabilizando una civilización que desembocó en la mítica reina, Cleopatra, modelo por excelencia. El procedimiento apuntaba a una programática declaración de intenciones sobre la asunción del poder por parte de extranjeros. La evidencia de los papiros en todos los géneros, pero en especial el administrativo social, así lo demuestran. Al Hiba, una ciudad dedicada a la retórica, impartió las enseñanzas en varias lenguas dominantes, como el vigente demótico, el pujante latín o el exhausto jeroglífico faraónico. La aparición de sistemas de declinaciones o de conjugaciones parecieron extraños a la mentalidad vernácula, pero acabaron por imponerse. La escritura en las épocas ptolemaica y romana se caracteriza por un aumento de signos y sincretismos entre ellos. Incluso los más corrientes llegan a ser irreconocibles. Sin embargo los juegos gráficos no son inventos del momento sino concentraciones en una sola forma de distintas funciones gramaticales y léxicas. Veamos un ejemplo: la composición de un gato $(\mathrm{mj} w)$ coronado con el signo del dios solar ( $r$ ) presenta el signo de la vida ('nj) expresa el valor de (dj-'nj-mj-r), "dotado (dj) de la vida como ( $m j$ ) Rê $(r)$ " (Winand, 2013, 80). Ahora bien, con el paso de los siglos acabó imponiéndose el más robusto pergamino.

Después del exilio babilónico, una parte del mundo judío se asienta en Alejandría. De esta comunidad a comienzos del siglo III antes de la era común, apenas hay noticias. La convivencia fue pacífica entre los grupos étnicos. La política cultural y el mecenazgo artístico de los Ptolomeos toleró tradiciones extranjeras. La imagen de los judíos de Alejandría en tiempos de Ptolomeo Il es la de una comunidad perfectamente integrada y aceptada en la ciudad acorde con la política real. La necesidad pragmática de traductores bilingües y trilingües acabó por imponer su aceptación. Más tarde al cambio de era llegó a ser una próspera etnia que poblaba la isla de Elefantina, en Asuán, la capital meridional. Por las fuentes más tardías, ya en tiempos romanos, los autores establecen para el reinado del Ptolomeo II Filadelfo (285-246 a. EC) la traducción al griego de la Torá o Pentateuco, los cinco primeros libros del Génesis. El hecho implicaba una voluntad de identidad diferenciada de la egipcia, la griega o la aramea. Para que esto fuera posible tuvieron que concurrir una serie de condiciones ideales, en la ficción de creación de una biblioteca. La imagen de un grupo dedicado a tales ficciones están descritas en forma de leyenda, que está expresada en la Carta de Aristeas, un escrito pseudoepigráfico de la segunda mitad del siglo II antes de nuera era.

Este escrito puede considerarse como la carta magna fundacional de los judíos de Alejandría, que justifica su regreso a Egipto. En estas condiciones ya no era necesario un nuevo Éxodo porque al rey Ptolomeo propició, a diferencia de los babilónicos, el modelo de rey helenístico, piadoso e interesado por la cultura y religión de los judíos. 
Como se pone de manifiesto en la parte más extensa de la misma, el simposio del rey con los traductores es cordial. Demetrio de Falerón figura como el bibliotecario que expone al rey los proyectos de su biblioteca universal. Ptolomeo envía una embajada a Eleazar, el Sumo Sacerdote de Jerusalén, con regalos para obtener de éste ejemplares de la Ley judía y un equipo de traductores, seis por cada tribu, es decir 72 , número que después se redondeará en 70 y que termina por dar el nombre histórico a la propia traducción de la Biblia de los Setenta, la Septuaginta. En la carta, Aristeas habla de un rey filósofo, mimético a la República de Platón. En ella el rey está acompañado de los traductores y de filósofos dispuestos a la tarea en una isla cercana. No es conocida pero ciertas teorías la identifican con la de Faros. El procedimiento de entendimiento ha permitido establecer una hermenéutica colectiva para los avances en la redacción. El trabajo reunía los eruditos y les proporcionaba material para interpretar y traducir. El resultado final fue una obra que ha perdurado como genuina entre los alejandrinos.

Durante la República romana en los ambientes jurídicos, Cicerón es el gran productor de documentos. Sus discursos y las cuestiones de oratoria forense han modelado el género. Los casos, las oraciones y la argumentación siguen con plena vigencia. A excepción de los discursos públicos de litigación en Demóstenes o la educación judicial de Isócrates ${ }^{4}$. La elaboración literaria alcanza un grado inigualado. A veces y a distancia, su intermediación le permite intervenir en los edictos anuales consulares o provinciales. En las decisiones del Senado toma parte activa y determinante. Las cláusulas indican el nivel estereotipado que alcanza la burocracia. Aquí las fórmulas legales devienen instancias protocolarias: consules alter ambove si iis videatur (los cónsules, o bien alguno de ellos o ambos si lo desean). En los documentos de oratoria forense se aprecian los tiempos del discurso. Desde la consecutio temporum sigue el pretérito, explicado por Cicerón como censuerunt, en el aconsejar o proceder en el juzgar la forma de pensar, como verbo principal (Albrecht, 2003: 75).

Para ir concluyendo, en el mundo judío, tanto la traducción de la Torá como el Pentateuco al griego han constituido obras álgidas del sincretismo en el pensamiento helenístico. En conjunto conforman la tradición de tolerancia y construcción de un mundo que va a ser reducido por la potencia romana en auge. El resurgir de la identidad nacional aparece con los Macabeos. Después de traducir el Pentateuco a comienzos del tercer siglo III, los diferentes libros del universo judío son interpretados y asimilados a las nuevas condiciones. De tal manera sucede que la potencia intelectual en pleno período de los últimos macabeos produce unas obras controvertidas entre la invención y la recreación históricas. El Eclesiástico, los de Judit y Tobit, y los Suplementos a los libros de

4 Isócrates, en el discurso previo, somete a crítica de los alumnos del orador las claras tendencias políticas, como ocurre con los filoespartanos (Signes Codoñer, 1998: 67). 
Estery Daniel aparecen por primera vez en historia sagrada. A su vez ciertos autores como Ezequiel el Trágico, o Filón el Viejo, para distinguir del propio Filón de Alejandría o Flavio Josefo determinan su primer momento esplendoroso ${ }^{5}$.

A partir del siglo II ensayarían prácticamente cualquier género en la literatura hasta entonces conocida por la tradición griega. En el teatro los intentos de resolver la pugna con el mito que había ocupado el clásico ateniense del siglo $\mathrm{V}$, ahora encontraban un cauce y salida en el género religioso helenístico aplicado a la Biblia. La tolerancia entre las comunidades dejó las manos libres para recrear la tragedia como memoria en los temas del desarraigo. En estas condiciones la imagen estereotipada del judío errante recordó el Éxodo en Ezequiel el Trágico. Más tarde, Flavio Josefo afirmaba su ancestral historia hebrea en las antigüedades judías.

El pensamiento bíblico nos introduce en el sentido de la experiencia hebraica. Está recorrido de principio a fin por arquetipos y símbolos primordiales que confieren unidad y sentido global al conjunto de los libros desde el Génesis hasta el Apocalipsis del evangelista Juan. En este contexto, se organiza y conforma el universo de las costumbres tradicionales de Israel a lo largo de varios milenios. Oscila entre lo mítico y lo histórico. En él confluyen unas experiencias históricas fundacionales aun no grabadas y un universo simbólico, que es elaborado con posterioridad como historia sagrada. En el universo mental del hebreo antiguo los ritos de alianza ocupan un lugar preferente y van conceptualizados en la consideración de libro sagrado para la Biblia. Todo ello aparece estructurado conforme a un paradigma básico de Exilio-Redención. El monoteísmo yahvista se revela como el principio básico y característico del pensamiento, ideal religioso en el universo simbólico bíblico. A partir de este momento toman carta de naturaleza las tesis de Teofrasto que considera al pueblo judío como muy recogidos en archivos como el epistolar de El Amarna.

\section{CONCLUSIONES}

En síntesis, el pensamiento protohistórico queda reflejado en los documentos conservados en archivos parietales, de papiros o de objetos votivos. Los signos que aparecen siguen visualmente las tríadas de Peirce en indicios, iconos y símbolos. Los aspectos gramaticales aparecen ya en el Neolítico en forma de pictogramas, ideogramas, logogramas, sílabarios, fonemas o, entre otros, determinativos. Los que mayor incidencia presentan son los iconos; $y$, en el sentido gramatical, logogramas y silabarios para el sumerio y su evolución posterior en el acadio; y en el egipcio ideogramas, fonogramas y determinativos.

5 La actividad en los ambientes alejandrinos convierte la ciudad en un eminente sincretismo judeohelenístico. 
La compilación de documentos como las tablillas de barro o los papiros se guardaban en archivos. Entre estos destacan los epistolares, como el de El Amarna en el Medio Egipto, donde se recogen diversas variedades de lenguas semíticas. El carácter preservado constituye la visibilidad del signo y su interpretación.

La Biblioteca de Alejandría representa el primer gran proyecto cultural de preservación de la escritura. En un recinto portuario se encontraban el Faro, el Museo y la propia Biblioteca. El primer encargado de catalogar los papiros fue el legendario Calímaco. También la ciudad de Misia, Pérgamo albergó una biblioteca importante para el conocimiento de la Antigüedad. Las experiencias históricas de los judíos aparecen reflejadas en el Antiguo Testamento, redacción helenística.

\section{REFERENCIAS BILIOGRÁFICAS}

AGUDO RUIZ, A. (2012). "Justiniano y la reforma de los estudios jurídicos". REDUR 10, 7-25.

ALAVEDRA i REGÀS, J. (2004). “Guía a los jeroglíficos del Antiguo Egipto, principios de semiótica jeroglífica". En Arte y nuevas tecnologías: Actas del X Congreso de la AES, Miguel Ángel Muro Munilla (coord.), 158-171. Logroño: Universidad de La Rioja.

ALBRECHT, M. von (2003). Cicero's Style. A Synopsis. Leiden / Boston: Brill.

ALONSO TRONCOSO, V. (2003). "Las primeras bibliotecas de Roma Romoteca)". Revista General de Información y Documentación 13, 37-49.

BARTHES, R, (1989). "Variaciones sobre la escritura”. En La escritura y la etimología del mundo, Riccardo Campa (ed.), 9-78. Buenos Aires: Sudamericana.

BENJAMIN, W. (2015). El autor como productor. Madrid: Casimiro.

CIVIL, M. (1982). "Studies on Early Dynastic Lexicography I". Oriens Antiquus 21, 1-26.

—— (1992). “Cuneiform”. En International Encyclopedia of Linguistics, W. Bright (ed.), volumen I, 322-325. Nueva York / Oxford: Oxford University Press.

COLL i CALAF, M. (1993). “La progressió teleològica a través de la regressió arqueològica. L'antropologia de Paul Ricoeur". Enrahonar 20, 17-30.

CORNU, G. (1983). "Écriture, peinture: Des calligrammes aux pictogrammes". Semiotica 44, 123-135.

ELIADE, M. (1973). Lo sagrado y lo profano. Madrid: Guadarrama.

ESCOLAR, H. (2001). La biblioteca de Alejandría. Madrid: Gredos.

FRANDSEN, P. J. 1997. “On Categorization and Metaphorical Structuring: Some Remarks on Egyptian Art and Language". Cambridge Archaeological Journal 7, 71-104.

GADAMER, H. G. (1996). Estética y hermenéutica. Madrid:Tecnos.

GONZÁLEZ BLANCO, A. (2006). "Aretalogías y experiencia didáctica”. En Koinos Logos. Homenaje al profesor José García López, E. Calderón, A. Morales y M. Valverde (eds.), 364-379. Murcia: Universidad de Murcia. 
DOCUMENTO Y REGISTRO GRÁFICO EN EL ORIGEN ORIENTAL DE LOS SIGNOS VISUALES

\section{PRECLÁSICOS Y LA PLENA VIGENCIA EN ARCHIVOS CONTEPORÁNEOS}

KLINKENBERG, Jean-Marie (2008). “Le rhéthorique dans la sémiotique: le composant créative du système". En Figures de la figure, Sémir Badir y Jean-Marie Klinkenberg (eds.), 35-56. Limoges: Presses Universitaries de Limoges.

MARCENÒ, Serena (2008). “Metis e Penelope. Questioni di metodo tra scritture, pitture e discorsi”. En Iconografia e storia dei concetti, Andrea L. Carbone (ed.), 33-49. Palermo: Duepunti.

MUÑíZ, Joaquín (1997; 1998). “Elaboración, conservación y custodia de las fuentes documentales escritas en la antigua Roma. Los archivos. I y II". Hispania antiqua 21, 403-429 y $22,371-400$.

SCHIPANI, Sandro (2010). "Los códigos de Justiniano como modelos de búsqueda de la consonantia en las transformaciones y reformas del derecho y de la propiedad, y los códigos modernos". Revista Chilena de Historia del Derecho 22, 137-148.

SELDEN, Daniel L. (1998). "Alibis". Classical Antiquity 17, 289-412.

SIGNES CODOÑER, Juan (1998). "El Panatenaico de Isócrates: 2. - Tema y finalidad del discurso". Emérita LXVI, 67-94.

VERNUS, Pascal (2011). "Naissance des hiéroglyphes et affirmation iconique du pouvoir: l'emblème du palais dans la genèse de l'écriture". En Actes Sud/Alphabets, Les premières cités et la naissance de l'écriture. Actes du colloque du 26 septembre 2009 Musée archéologique de Nice-Cemenelum, 27-58. Paris: Actes Sud.

WHITE, Hayden (2003). El texto histórico como artefacto literario y otros escritos. Barcelona / Buenos Aires / México: Paidós / ICE de la Universidad Autónoma de Barcelona. WINAND, Jean (2013). Les hiéroglyphes égyptiens. París: Presses Universitaires de France. 
